Supporting Information for:

\title{
CNS and CNP Iron(II) Mono-Iron Hydrogenase (Hmd) Mimics: Role of Deprotonated Methylene(acyl) and trans-Acyl Site in $\mathrm{H}_{2}$ Heterolysis
}

\author{
Yae In Cho, Gummadi Durgaprasad and Michael J. Rose* \\ Department of Chemistry, The University of Texas at Austin
}

Supporting Information Contents

page

X-ray data collection and refinement details

Figure S1. ORTEP diagram of CNPPre ligand precursor 4

Table S1. Crystal data and refinement parameters 5

Figure S2. (complete) Space-filling models of Fe-CNS and Fe-CNP 6

Figure S3. Infrared spectra of Fe-CNS, Fe-CNS' and Fe-CNS' treated with 2,6-lutidinium 7 bromide.

Figure S4. (A) ${ }^{1} \mathrm{H}$ NMR spectra of Fe-CNS and Fe-CNP in $\mathrm{C}_{6} \mathrm{D}_{6}$

(B) ${ }^{31} \mathrm{P}$ NMR spectrum of Fe-CNP in $\mathrm{C}_{6} \mathrm{D}_{6}$

Figure S5. ' ${ }^{H}$ NMR spectrum of Fe-CNS' and conjugate phenol in $\mathrm{C}_{6} \mathrm{D}_{6}$

Figure S6. ' $\mathrm{H}$ NMR spectra of $\mathrm{D}_{2}$ activation by Fe-CNP' with or without the presence of substrate $\left.{ }^{(\mathrm{Me}} \mathrm{Im}^{+}\right)$.

Figure S7. ${ }^{13} \mathrm{C}$ NMR spectra (A: H-decoupled; B: H-coupled) of Fe-CNP' $+\mathbf{D}_{2}$ in THF 


\section{X-ray Data Collection and Refinement Details}

CNPPre: Crystals grew as blocks from $\mathrm{Et}_{2} \mathrm{O}$ solution of $\mathrm{CNP}^{\text {Pre }}$ at $-20^{\circ} \mathrm{C}$. The analyzed crystal was cut from a larger crystal and had approximate dimensions $0.23 \times 0.11 \times 0.09 \mathrm{~mm}$. The data were collected on a Rigaku AFC12 diffractometer with a Saturn 724+ CCD using a graphite monochromator with MoKa radiation $(\lambda=0.71073 \AA)$. The data were collected at $100 \mathrm{~K}$ using a Rigaku XStream low temperature device. Data reduction were performed using the Rigaku Americas Corporation's Crystal Clear version $1.40 .{ }^{1}$ The structure was solved by direct methods using SIR $2004^{2}$ and refined by full-matrix least-squares on $\mathrm{F}^{2}$ with anisotropic displacement parameters for the non-H atoms using SHELXL-2014/7. ${ }^{3}$ Structure analysis was aided by use of the programs PLATON98 ${ }^{4}$ and WinGX ${ }^{5}$ The hydrogen atoms on carbon were calculated in ideal positions with isotropic displacement parameters set to $1.2 \times U_{\text {eq }}$ of the attached atom $\left(1.5 \times U_{\text {eq }}\right.$ for methyl hydrogen atoms).

The function, $\Sigma w\left(\left|F_{0}\right|^{2}-\left|F_{C}\right|^{2}\right)^{2}$, was minimized, where $w=1 /\left[\left(\sigma\left(F_{0}\right)\right)^{2}+\left(0.0529^{*} P\right)^{2}+\left(3.6702^{*} P\right)\right]$ and $P=\left(\left|F_{0}\right|^{2}+2\left|F_{C}\right|^{2}\right) / 3 . R_{w}\left(F^{2}\right)$ refined to 0.106 , with $R(F)$ equal to 0.039 and a goodness of fit, $S,=1.06$. Definitions used for calculating $R(F), R_{w}\left(F^{2}\right)$ and the goodness of fit, $S$, are given below. ${ }^{6}$ The data were checked for secondary extinction effects but no correction was necessary. Neutral atom scattering factors and values used to calculate the linear absorption coefficient are from the International Tables for X-ray Crystallography (1992). ${ }^{7}$

Fe-CNS: Crystals grew as needles by layering pentane on the DCM solution of Fe-CNS at $-25^{\circ} \mathrm{C}$. The analyzed crystal was cut from a larger crystal and had approximate dimensions $0.10 \times 0.08$ $\times 0.05 \mathrm{~mm}$. The data were collected on a Rigaku AFC12 diffractometer with a Saturn 724+ CCD using a graphite monochromator with Mo Ka radiation $(\lambda=0.71073 \AA)$. The data were collected at $153 \mathrm{~K}$ using a Rigaku XStream low temperature device. Data reduction were performed using the Rigaku Americas Corporation's Crystal Clear version 1.40. ${ }^{1}$ The structure was solved by direct methods using SIR $2004^{2}$ and refined by full-matrix least-squares on $\mathrm{F}^{2}$ with anisotropic displacement parameters for the non-H atoms using SHELXL-2014/7. ${ }^{3}$ Structure analysis was aided by use of the programs PLATON98 ${ }^{4}$ and WinGX. ${ }^{5}$ The hydrogen atoms on carbon were calculated in ideal positions with isotropic displacement parameters set to $1.2 \times U_{\text {eq }}$ of the attached atom (1.5 $\times U_{\text {eq }}$ for methyl hydrogen atoms).

The function, $\Sigma w\left(\left|F_{0}\right|^{2}-\left|F_{C}\right|^{2}\right)^{2}$, was minimized, where $w=1 /\left[\left(\sigma\left(F_{0}\right)\right)^{2}+\left(1.5194^{\star} P\right)\right]$ and $P=\left(\left|F_{0}\right|^{2}\right.$ $\left.+2\left|F_{C}\right|^{2}\right) / 3 . R_{w}\left(F^{2}\right)$ refined to 0.043 , with $R(F)$ equal to 0.020 and a goodness of fit, $S,=1.15$. Definitions used for calculating $R(F), R_{w}\left(F^{2}\right)$ and the goodness of fit, $S$, are given below. ${ }^{6}$ The data were checked for secondary extinction effects but no correction was necessary. Neutral atom scattering factors and values used to calculate the linear absorption coefficient are from the International Tables for X-ray Crystallography (1992). ${ }^{7}$

Fe-CNP: Crystals grew as small clusters of orange crystals by slow evaporation (THF/pentane). The analyzed crystal was cut from a cluster of crystals and had approximate dimensions $0.11 \times$ $0.06 \times 0.06 \mathrm{~mm}$. The data were collected on an Agilent Technologies SuperNova Dual Source diffractometer using a $\mu$-focus $\mathrm{Cu} \mathrm{K \alpha}$ radiation source $(\lambda=1.5418 \AA$ ) with collimating mirror monochromators. A total of 1064 frames of data were collected using w-scans with a scan range of $1^{\circ}$ and a counting time of 9 seconds per frame with a detector offet of $\pm 41.4^{\circ}$ and 25 seconds per frame with a detector offset of $\pm 112.0^{\circ}$. The data were collected at $100 \mathrm{~K}$ using an Oxford Cryostream low temperature device. Data collection, unit cell refinement and data reduction were performed using Agilent Technologies CrysAlisPro V 1.171.37.31. ${ }^{8}$ The structure was solved by 
direct methods using SHELXT ${ }^{3}$ and refined by full-matrix least-squares on $\mathrm{F}^{2}$ with anisotropic displacement parameters for the non-H atoms using SHELXL-2014/7. ${ }^{3}$ Structure analysis was aided by use of the programs PLATON98 ${ }^{4}$ and WinGX. ${ }^{5}$ The hydrogen atoms were calculated in ideal positions with isotropic displacement parameters set to $1.2 \times U_{\text {eq }}$ of the attached atom (1.5 $\times U_{\text {eq }}$ for methyl hydrogen atoms). The data crystal was twinned with twin law determined using CrysAlisPro.

The function, $\Sigma \mathrm{w}\left(\left|\mathrm{F}_{0}\right|^{2}-\left|\mathrm{F}_{\mathrm{C}}\right|^{2}\right)^{2}$, was minimized, where $\mathrm{w}=1 /\left[\left(\sigma\left(\mathrm{F}_{0}\right)\right)^{2}+\left(0.1853^{\star} \mathrm{P}\right)^{2}\right]$ and $\mathrm{P}=\left(\left|\mathrm{F}_{0}\right|^{2}\right.$ $\left.+2\left|F_{C}\right|^{2}\right) / 3$. $R_{w}\left(F^{2}\right)$ refined to 0.241 , with $R(F)$ equal to 0.093 and a goodness of fit, $S,=1.04$. Definitions used for calculating $R(F), R_{w}\left(F^{2}\right)$ and the goodness of fit, $S$, are given below. ${ }^{6}$ The data were checked for secondary extinction effects but no correction was necessary. Neutral atom scattering factors and values used to calculate the linear absorption coefficient are from the International Tables for X-ray Crystallography (1992). ${ }^{7}$

\section{X-ray Refinement References}

1) CrystalClear 1.40 (2008). Rigaku Americas Corportion: The Woodlands, TX.

2) SIR2004. A program for crystal structure solution. Altomare A., Burla M.C., Caliandro, M., Camalli M., Carrozzini, B., Cascarano G.L., De Caro, L., Giacovazzo C., Polidori G., Spagna R. J. Appl. Cryst., 2005, 38, 381-388.

3) SHELXL-2014/7 (2015) Sheldrick, G. M. Acta Cryst., C71, 9-18.; SHELXT. An Integrated Space Group and Crystal Structure Determination Program.

4) PLATON (1998). A Multipurpose Crystallographic Tool. Utrecht University, The Netherlands. Spek, A. L.

5) WinGX 1.64. (1999); An Integrated System of Windows Programs for the Solution, Refinement and Analysis of Single Crystal X-ray Diffraction Data. Farrugia, L. J. J. Appl. Cryst. 32. 837838.

6) $R \mathrm{w}\left(F^{2}\right)=\left\{\Sigma \mathrm{w}\left(\left|F_{0}\right|^{2}-\left|F_{\mathrm{c}}\right|^{2}\right)^{2} / \Sigma \mathrm{w}\left(\left|F_{0}\right|\right)^{4}\right\}^{1 / 2}$, where $\mathrm{w}$ is the weight given each reflection.

$\left.R(F)=\Sigma\left(\left|F_{0}\right|-\left|F_{\mathrm{c}}\right|\right) / \Sigma\left|F_{0}\right|\right\}$ for reflections with $F_{0}>4\left(\sigma\left(F_{0}\right)\right)$.

$S=\left[\Sigma \mathrm{w}\left(\left|F_{0}\right|^{2}-\left|F_{\mathrm{c}}\right|^{2}\right)^{2} /(n-p)\right]^{1 / 2}$, where $\mathrm{n}$ is the number of reflections and $\mathrm{p}$ is the number of refined parameters.

7) International Tables for X-ray Crystallography (1992). Vol. C, Tables 4.2.6.8 and 6.1.1.4, A. J. C. Wilson, editor, Boston: Kluwer Academic Press.

8) CrysAlisPro. Agilent Technologies (2013). Agilent Technologies UK Ltd., Oxford, UK, SuperNova CCD System, CrysAlicPro Software System, 1.171.37.31. 


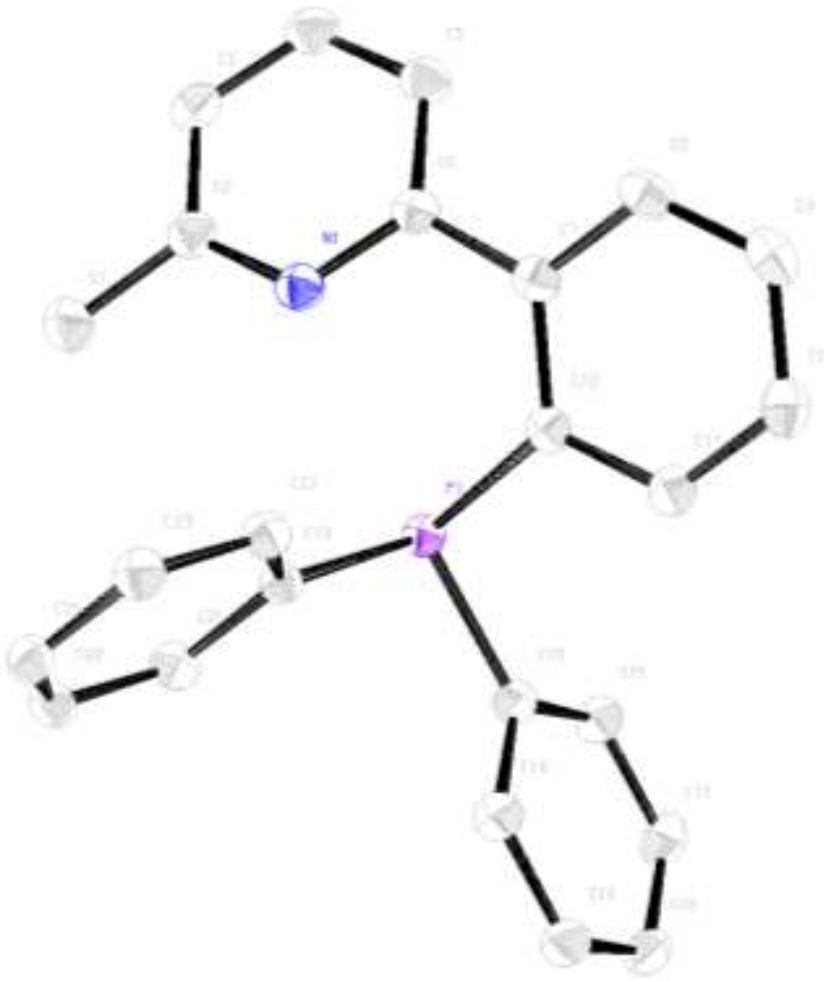

Figure S1. ORTEP diagram (50\% thermal ellipsoids) for CNPPre ligand precursor. $\mathrm{H}$ atoms are omitted for sake of clarity. Color scheme: carbon (grey); nitrogen (blue); phosphorous (purple). 


\begin{tabular}{|c|c|c|c|}
\hline & Fe-CNS & Fe-CNP & CNPPre \\
\hline $\begin{array}{r}\text { Empirical } \\
\text { formula }\end{array}$ & $\mathrm{C}_{16} \mathrm{H}_{12} \mathrm{FeINO}_{3} \mathrm{~S}$ & $\mathrm{C}_{27} \mathrm{H}_{19} \mathrm{FeINO}_{3} \mathrm{P}$ & $\mathrm{C}_{24} \mathrm{H}_{20} \mathrm{NP}$ \\
\hline $\begin{array}{r}\text { Molecular } \\
\text { formula }\end{array}$ & {$\left[\mathrm{Fe}^{\prime \prime}(\mathrm{CNS})(\mathrm{CO})_{2} \mathrm{l}\right]$} & {$\left[\mathrm{Fe}^{\prime \prime}\left(\mathrm{CNP}^{\mathrm{Ph} 2}\right)(\mathrm{CO})_{2} \mathrm{l}\right]$} & $\mathrm{CH}_{3} \mathrm{C}_{5} \mathrm{H}_{3} \mathrm{NC}_{6} \mathrm{H}_{4} \mathrm{P}\left(\mathrm{C}_{5} \mathrm{H}_{5}\right)_{2}$ \\
\hline $\mathrm{FW}$ & 481.08 & 619.15 & 353.38 \\
\hline Color & Red & Orange & Colorless \\
\hline Habit & Needles & Clusters & Prism \\
\hline Size $(\mathrm{mm})$ & $0.10 \times 0.08 \times 0.05$ & $0.11 \times 0.06 \times 0.06$ & $0.23 \times 0.11 \times 0.09$ \\
\hline $\mathrm{T}(\mathrm{K})$ & $153(2)$ & $173(2)$ & $100(2)$ \\
\hline$\lambda(\AA)$ & 0.71073 & 1.54184 & 0.71073 \\
\hline Lattice & Orthorhombic & Triclinic & Monoclinic \\
\hline $\begin{array}{l}\text { Space } \\
\text { group }\end{array}$ & $P 2{ }_{1} 2_{1} 2_{1}$ & $P-1$ & $C 2 / c$ \\
\hline$a(\AA)$ & $7.2977(6)$ & $10.6272(14)$ & $18.569(3)$ \\
\hline$b(\AA)$ & $10.7837(8)$ & $10.846(2)$ & $11.9238(18)$ \\
\hline$c(\AA)$ & $20.6626(16)$ & $12.1679(18)$ & $17.980(3)$ \\
\hline$\alpha\left(^{\circ}\right)$ & 90 & $66.269(16)$ & 90 \\
\hline$\beta\left(^{\circ}\right)$ & 90 & $72.377(12)$ & $112.260(3)$ \\
\hline$\gamma\left(\left(^{\circ}\right)\right.$ & 90 & $79.914(14)$ & 90 \\
\hline$V\left(\AA^{3}\right)$ & $1626.1(2)$ & $1221.4(4)$ & $3684.2(10)$ \\
\hline$z$ & 4 & 2 & 8 \\
\hline$d_{\text {calc }}\left(g / \mathrm{cm}^{3}\right)$ & 1.965 & 1.683 & 1.274 \\
\hline$\mu\left(\mathrm{mm}^{-1}\right)$ & 2.967 & 15.736 & 0.156 \\
\hline GOF on $F^{2}$ & 1.151 & 1.039 & 1.056 \\
\hline $\begin{array}{l}R \text { indices } \\
{[1>2 \sigma(l)]}\end{array}$ & $\begin{array}{c}R 1=0.0201 \\
w R 2=0.0423\end{array}$ & $\begin{array}{c}R 1=0.0930 \\
w R 2=0.2335\end{array}$ & $\begin{array}{c}R 1=0.0386 \\
w R 2=0.1001\end{array}$ \\
\hline $\begin{array}{r}R \text { indices } \\
\text { all data }\end{array}$ & $\begin{array}{c}R 1=0.0210 \\
w R 2=0.0426\end{array}$ & $\begin{array}{c}R 1=0.1049 \\
w R 2=0.2414\end{array}$ & $\begin{array}{c}R 1=0.0453 \\
w R 2=0.1059\end{array}$ \\
\hline
\end{tabular}

Table S1. Crystal data and refinement parameters for Fe-CNS, Fe-CNP and CNPPre . 

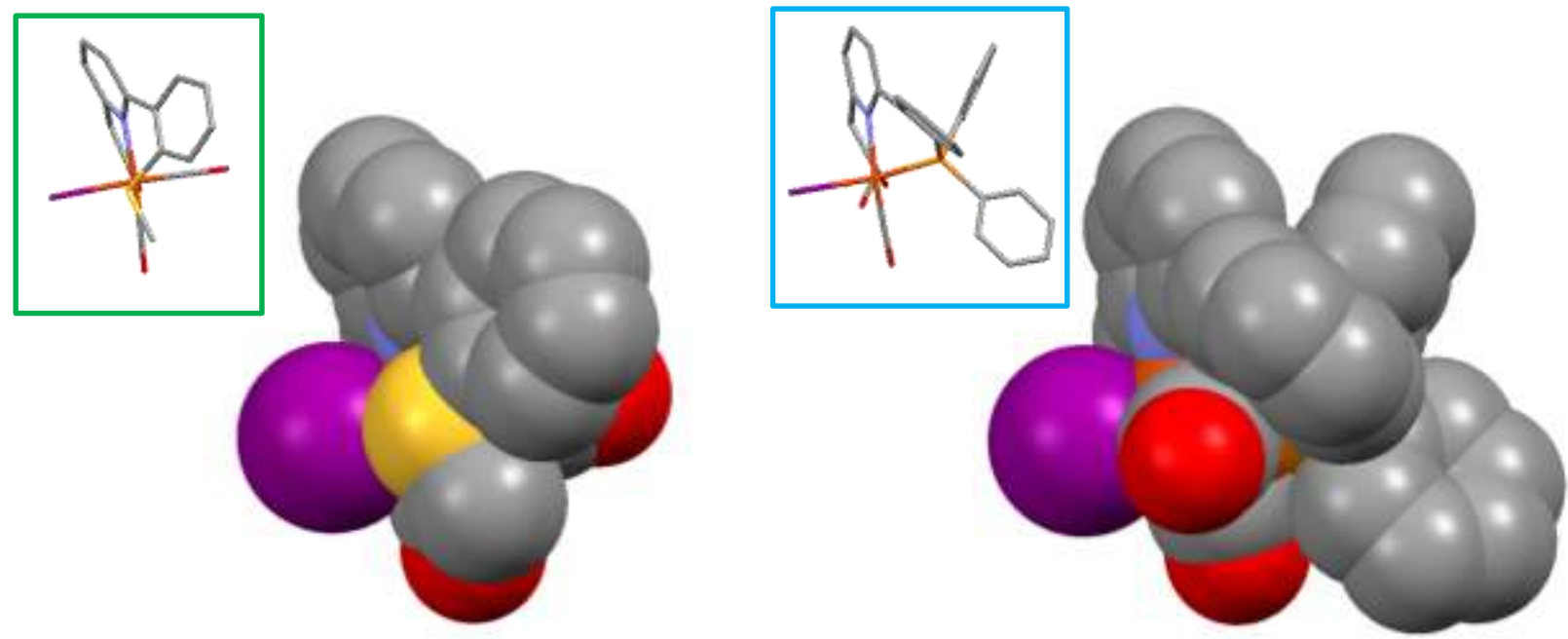

Figure S2. Complete Space-filling models of Fe-CNS (left) and Fe-CNP (right). Each inset represents the capped-sticks model of the larger structure at the same angle. Note that in each case, the bulkiest groups are located away from the site of iodide ligation. Color scheme: carbon (grey); nitrogen (blue); iodine (dark magenta); sulfur (yellow); phosphorous (orange). Hydrogen atoms are omitted for clarity. 


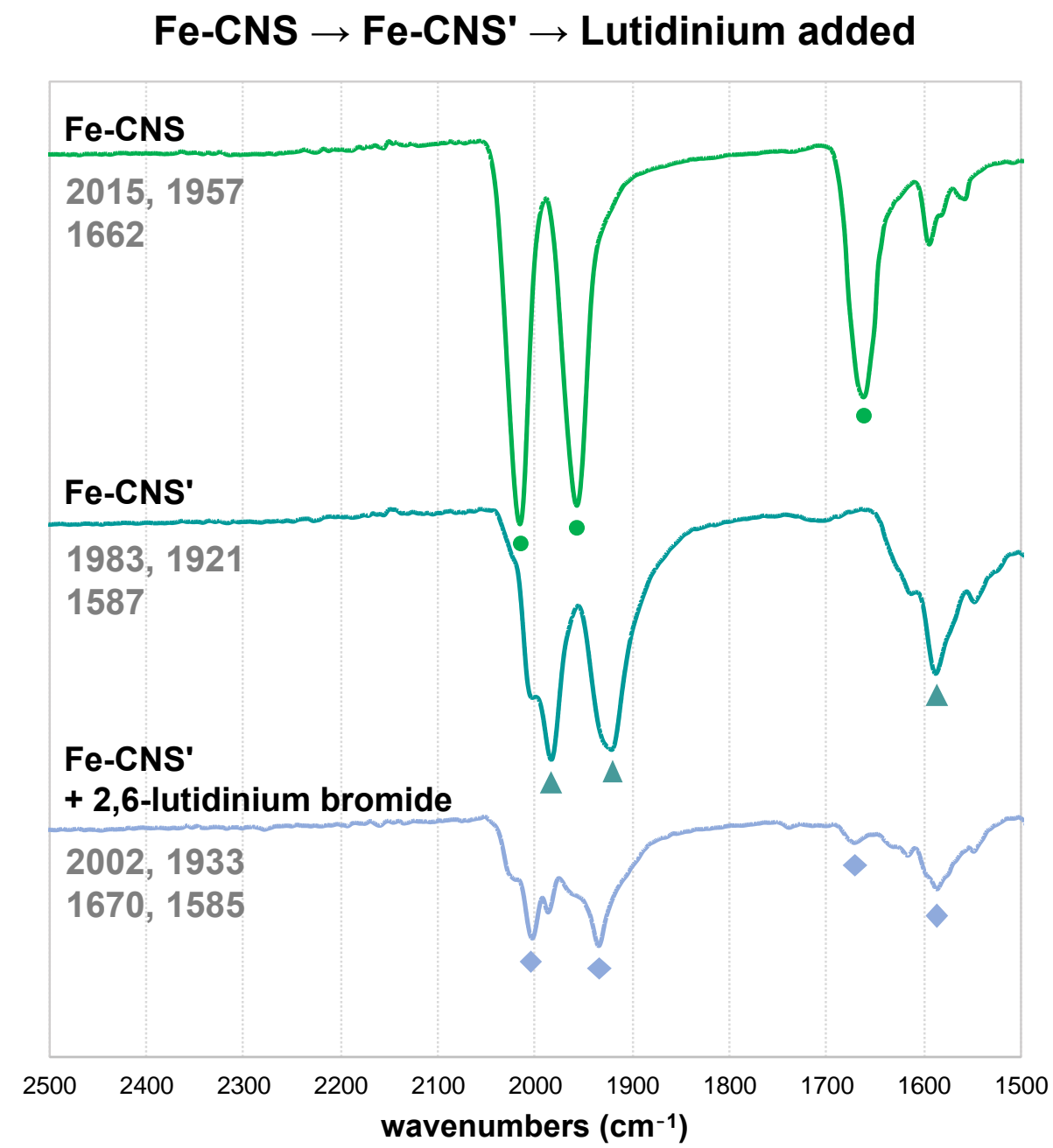

Figure S3. Infrared spectra of Fe-CNS (top), Fe-CNS' (middle), and Fe-CNS' treated with 2,6lutidinium bromide as a proton source (bottom). 


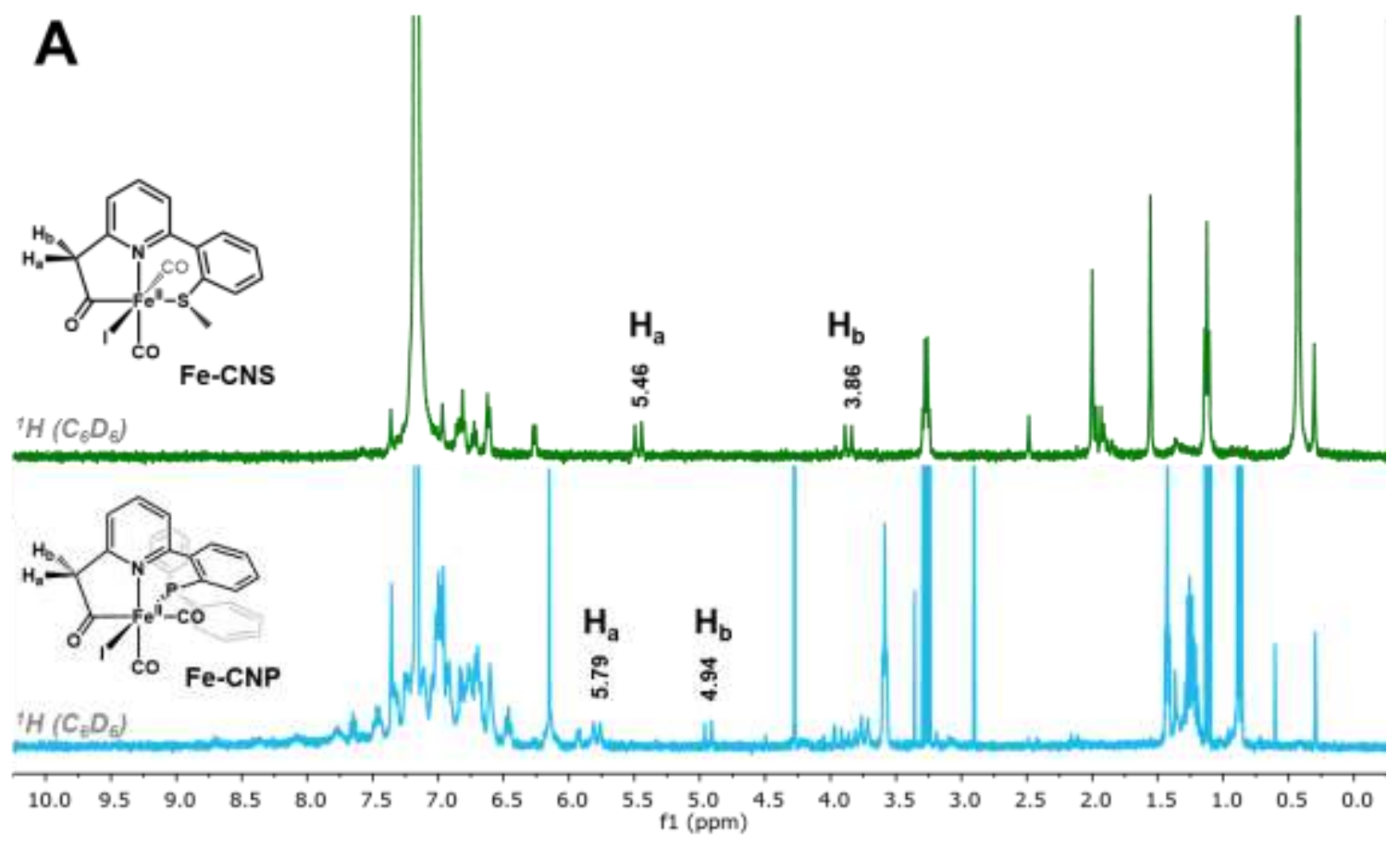

\section{B}

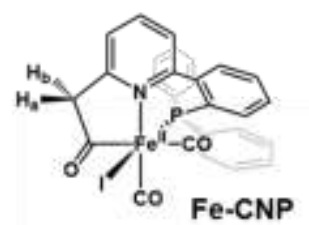

$\operatorname{sip}\left(C_{6} D_{6}\right)$

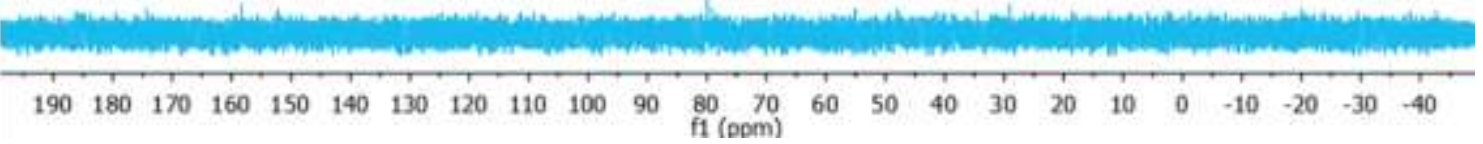

Figure S4. (A) ${ }^{1} \mathrm{H}$ NMR spectrum of Fe-CNS (top) and Fe-CNP (bottom) in $\mathrm{C}_{6} \mathrm{D}_{6}$.

(B) ${ }^{31} \mathrm{P}$ NMR spectrum of Fe-CNP in $\mathrm{C}_{6} \mathrm{D}_{6}$. 


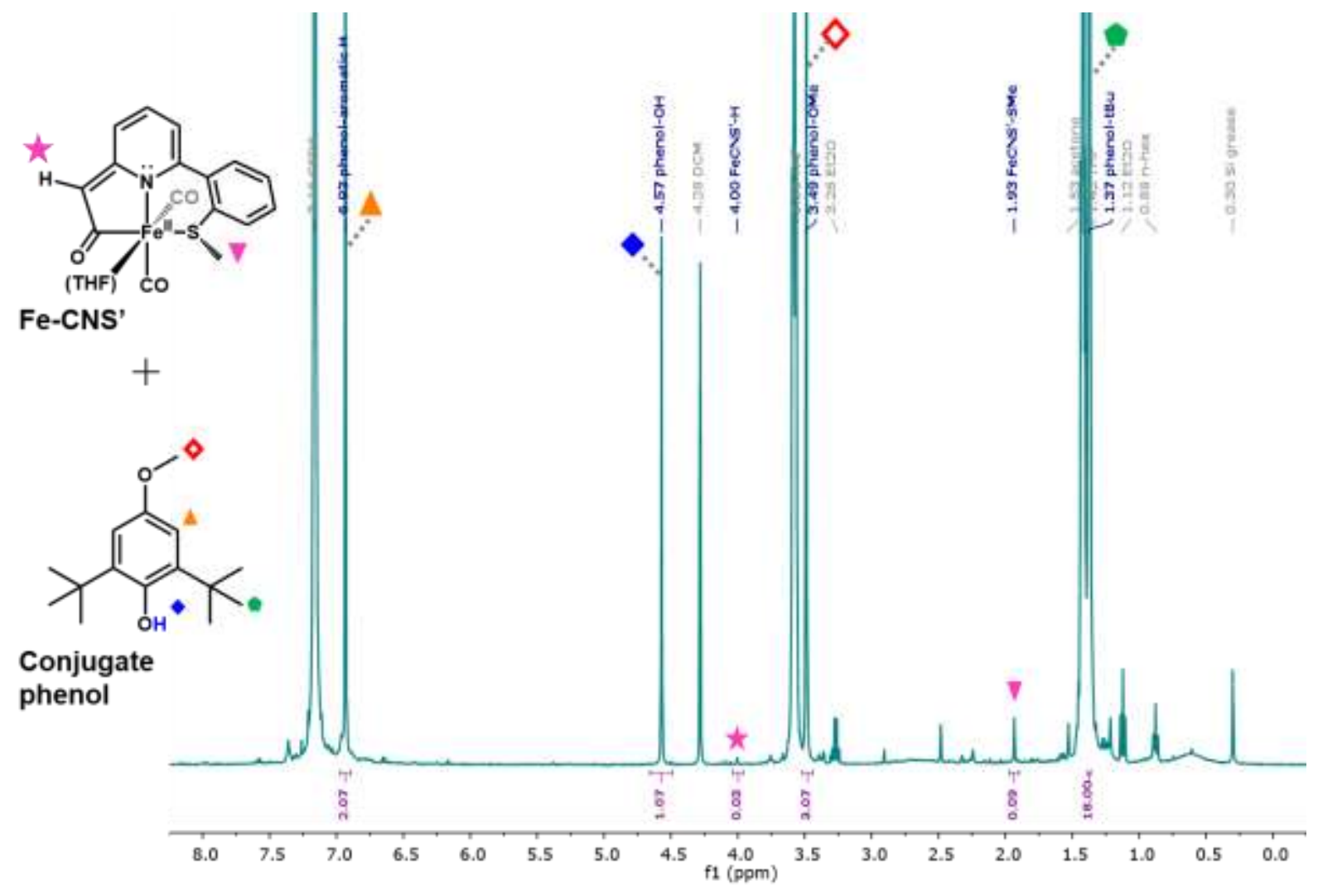

Figure S5. 'H NMR spectrum $\left(\mathrm{C}_{6} \mathrm{D}_{6}\right)$ of Fe-CNS' and conjugate phenol showing solvent impurities after the deprotonation of Fe-CNS with the bulky phenolate base. 

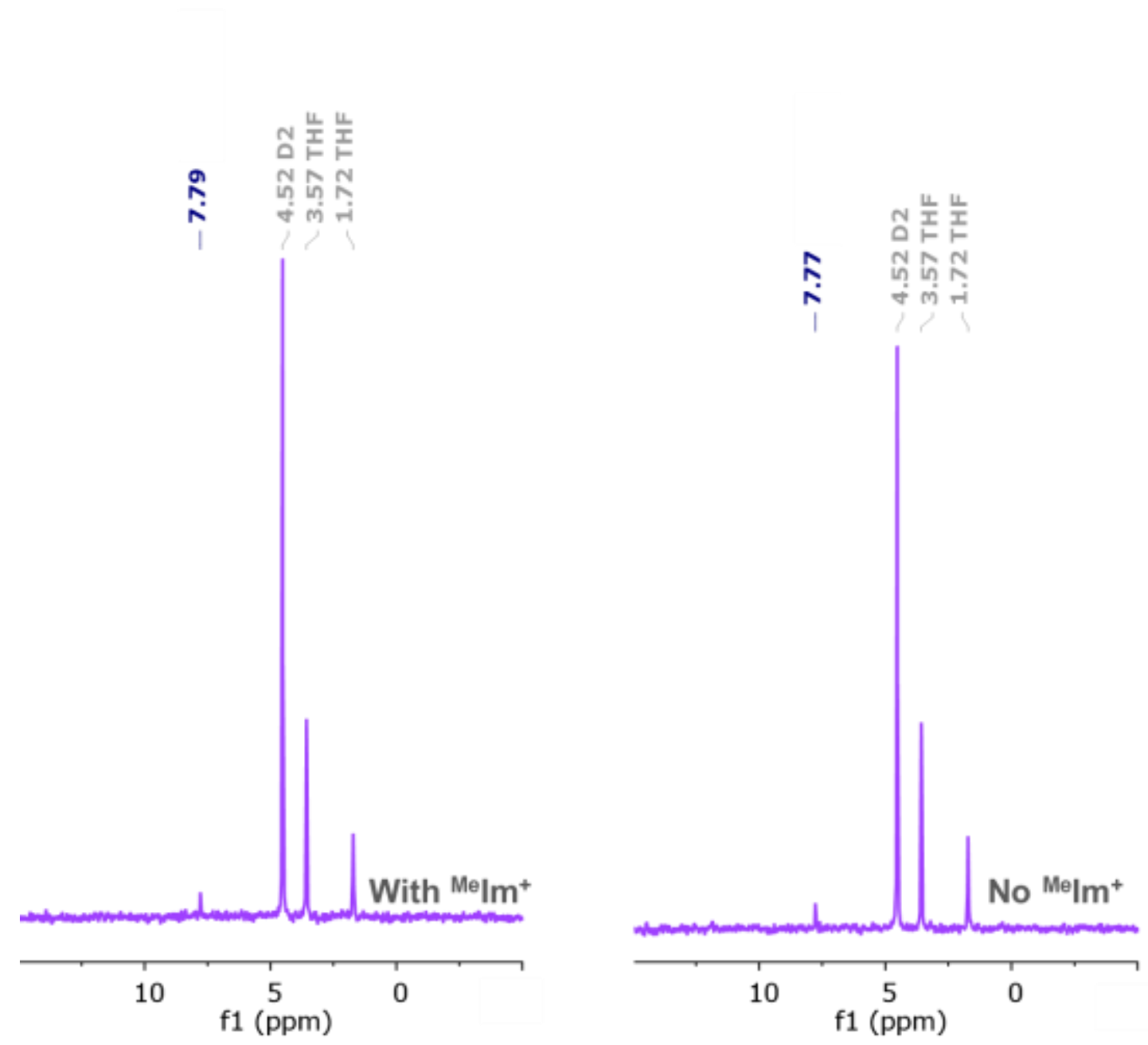

Figure S6. ${ }^{2} \mathrm{H}$ NMR spectra of $\mathrm{D}_{2}$ activation by Fe-CNP' with or without the presence of substrate $\left({ }^{\mathrm{Me}} \mathrm{Im}^{+}\right)$in THF. 


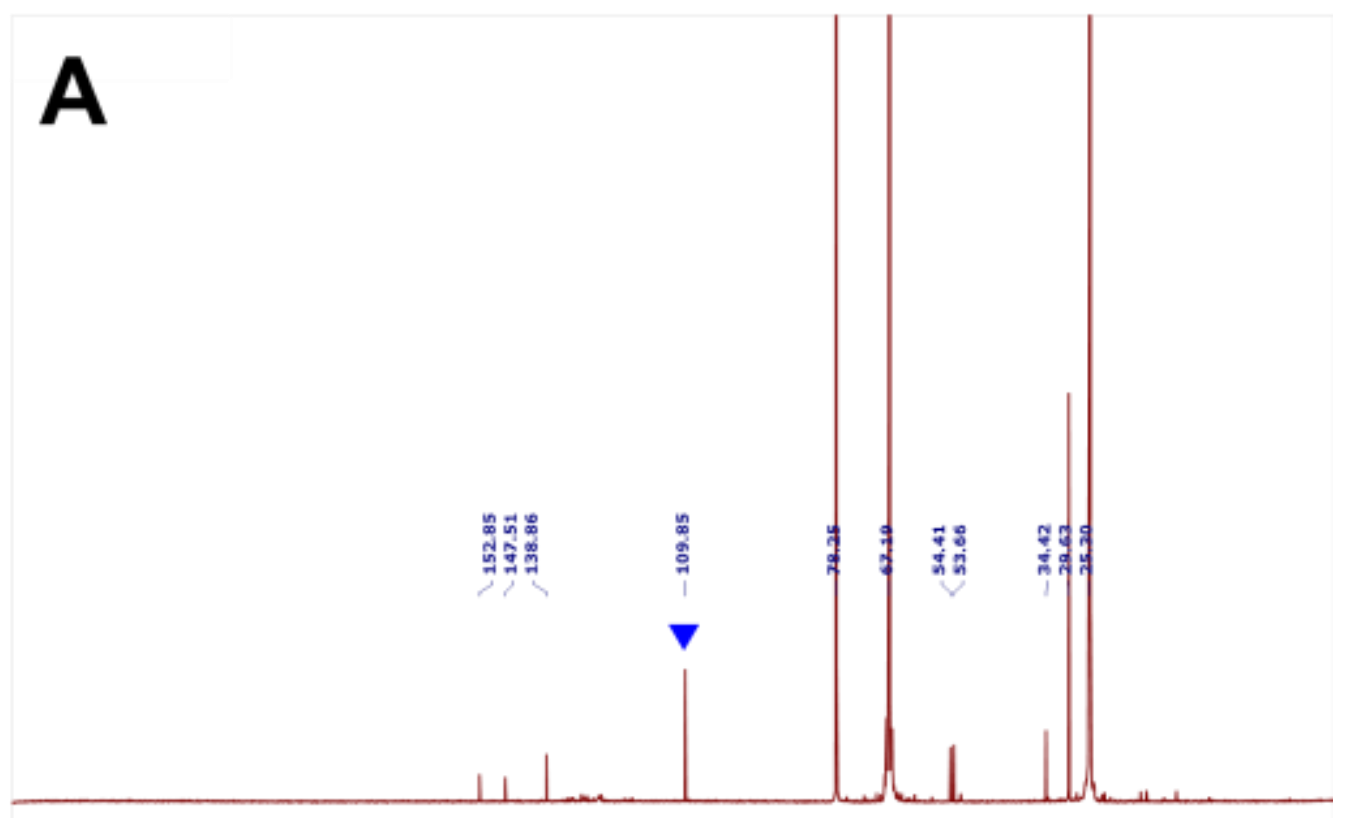

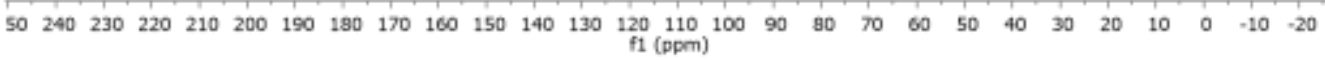

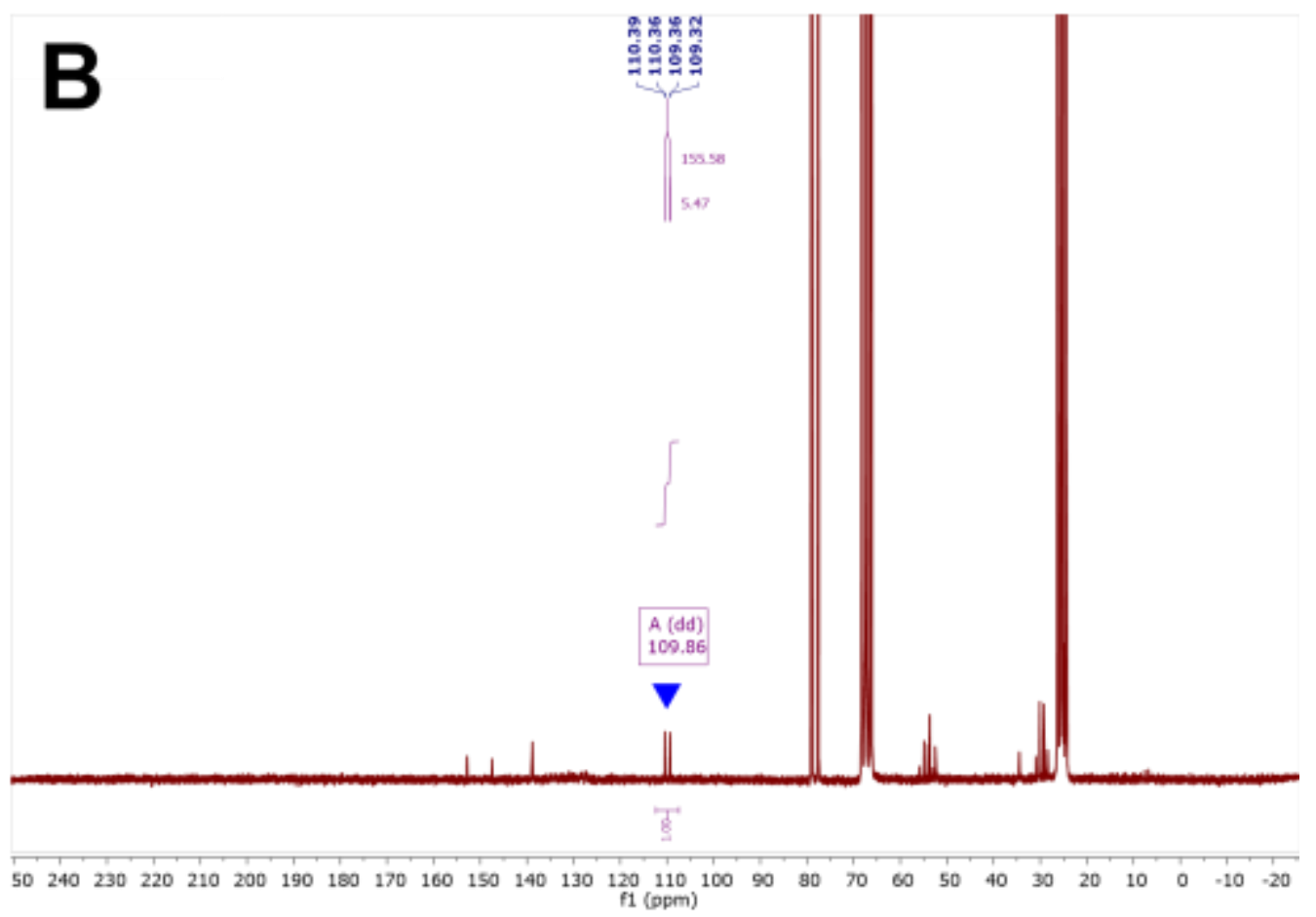

Figure S7. (A) H-decoupled and (B) H-coupled ${ }^{13} \mathrm{C}$ NMR spectra (THF) of Fe-CNP' treated with $\mathrm{D}_{2}$ showing methenyl-CH resonance at $109.85 \mathrm{ppm}$ and $109.86 \mathrm{ppm}(\mathrm{J}=$ $155.58,5.47 \mathrm{~Hz}$ ), respectively; no $C$ - $D$ coupling was observed. 